\title{
Effect of Silane Coupling Treatment on Microfracture in Plastics Reinforced with Plain Woven Glass Fabric
}

\author{
Hideki Ichihashi* ${ }^{*}$, Hiroyuki Hamada* ${ }^{*}$, Nobuo Ikuta* ${ }^{3}$, and Zenichiro Maekawa* 2 \\ *1 Kyoto Institute of Technology, Matsugasaki, Sakyo-ku, Kyoto, 606; Ube Industries Ltd., \\ Nakamiya-kitamachi, Hirakata, 573 Japan \\ ${ }^{*}$ Faculty of Textile Science, Kyoto Institute of Technology, Matsugasaki, Sakyo-ku, Kyoto, \\ 606 Japan \\ ${ }^{*}$ Osaka Municipal Technical Research Institute, Morinomiya, Joto-ku, Osaka, 536 Japan
}

\begin{abstract}
Effect of silane coupling treatment of glass fibers on mechanical properties of single-laminate epoxy resin reinforced with plain-woven glass fabric was studied. The microfracture along transverse fibers during tensile test was recorded on a video recorder and analyzed with image processing. In order to examine the effect of interfacial reinforcement on the initial microfracture stress and strain, glass fibers were treated with silane coupling agents at different concentrations. The initial microfracture stress and strain increased with silane concentration. At low concentrations, however, initial microfracture stress and strain did not increase. The reinforcement in warp direction was more improved than that in weft direction. The scanning electron microscopic observation of warp and weft fibers at the fracture surface showed no difference in adhesion between two tensile directions. From the observation of cross sections of the specimens, the fabric structure such as the expansion of fiber bundle or the degree of bending of the fibers, was different between warp and weft directions, which suggested that the fabric structure affected the microfracture stress and strain.
\end{abstract}

\section{Introduction}

Silane coupling treatment is widely used in manufacturing of glass fibers in order to reinforce fiber/matrix interfaces in polymer matrix composites. Silane coupling agents strengthen the interface, making chemical bonding between glass surface and resin. There are many factors in silane treatment to obtain the composite performance; reactivity to resin or glass $(1,2)$, structure of silane condensates at the interface $[3,4]$, treatment conditions (5-9), evaluation methods $[10-15]$ and so on. The mechanism of reinforcement by silane treatment has not been sufficiently clarified in practical application of silanes on glass fibers.

Generally, embedded single-filament test has been used to evaluate the interfacial properties. We have studied the effects of silane bonding state on mechanical properties of the interface using a modified embedded singlefilament test and silane fixation measurement $[16,17)$. The interfacial properties between glass fibers and resin have been gradually clarified using such procedures. For usual glass cloth composites, not for monofilament glass. resin composites in the single filament test, fabric structure and fiber orientation should be taken into consideration to interpret the interfacial effect on the mechanical properties of composites. In this study, a sheet of plainwoven fabric is selected as one of practical reinforcing fabrics. The effect of silane treatment on the mechanical properties was examined for warp and weft fibers in a plain-woven composite.

A characteristic property of woven fabric composites is a knee point in the stress-strain curve as shown in Fig. 1. It is known that the knee point appears in consequ. ence of microfracture as transverse cracking. Sun et at. $[18,19]$ studied the relation between tensile properties of woven fabric composites and microfracture by observ ing the fracture behavior in detail. Ishikawa and Chou [20-22] calculated tensile properties of woven fabric composites based on the microfracture. We proposed an evaluation technique for the appearance of microfracture by using an image analyzer [23]. However, the effect of surface treatment of fibers on the behavior of the micro. 


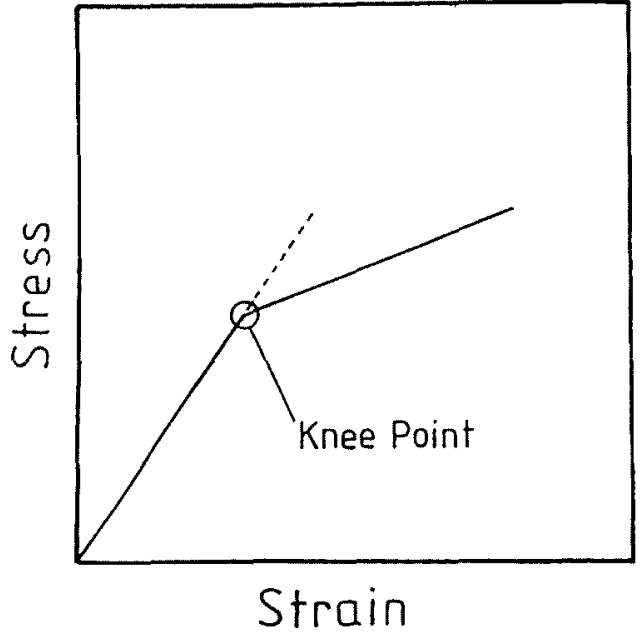

Fig. 1 Schematic of knee point.

fracture has not been reported

Initial microfracture is selected in this study as a mechanical property to evaluate the interfacial property. Silane coupling treatments at various concentrations are performed to vary the adhesion at the interface. Even in the plain-woven fabric, the fabric strcture is geometrically different between warp and wety directions even for the fabrics with the same weaving density, the same number of filaments and the same diameter of filaments. The difference arises from the weaving due to warp ten sion, filling tension, beating motion and so on. To discuss the effect of the fabric structure, tensile tests along warp and weft fibers were also carried out.

\section{Experimental}

\subsection{Materials}

Glass fabric used in this syudy was plain-woven cloth (Glasron Cloth MS251, Asahi Fiber Glass). Glass cloth had been heat-cleaned at the final stage of fabrication. Weaving densities of both warp and weft were 19 yarns/25 mm. Both warp and weft yarns consisted of 3000 glass filaments whose was $9 \mu \mathrm{m}$ diamenter.

$\gamma$-Anilinopropyltrimethoxysilane (AnPS) was used for the surface treatment of glass cloth. Solutions of silane coupling agent were prepared by hydrolyzing and dissolving different amounts of AnPS in aqueous $0.2 \mathrm{M}$ acetic acid solutions. Silane concentration was varied from 0 to $2 \%$ by weight. Glass cloth was immersed into the silane solution for a few minutes and heated at $90{ }^{\circ} \mathrm{C}$ for

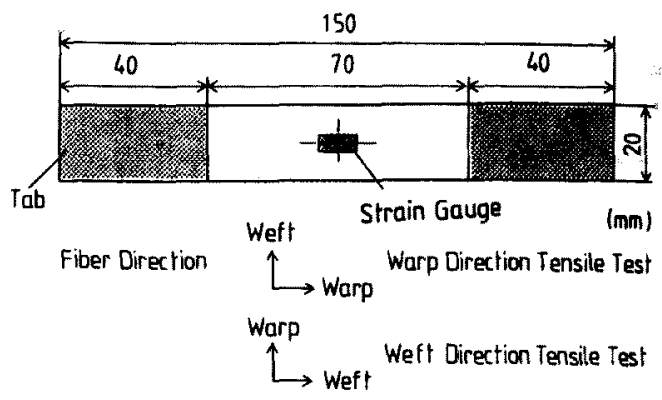

Fig. 2 Shape of specimen.

20 min after the immersion.

The matrix resin was bisphenol-A type epoxy resin (Epikote 828, Yuka-Shell) and the hardener was triethylenetetramine. The 100 patrs of resin was mixed with 11 parts of the hardener. In the preparation of single-laminate glass cloth composite, the mixture was defoamed in the vacuum oven at $50{ }^{\circ} \mathrm{C}$ for $10 \mathrm{~min}$, impreg. nated into glass cloth, and defoamed in the vacuum oven at $50{ }^{\circ} \mathrm{C}$ for $10 \mathrm{~min}$ again. The glass cloth and resin were put between glass plates and cured at $50{ }^{\circ} \mathrm{C}$ for 80 min and post-cured at $100^{\circ} \mathrm{C}$ for $60 \mathrm{~min}$ at $10 \mathrm{kPa}$. The thickness of the plate was about $0.3 \mathrm{~mm}$ and the volume fraction of glass fiber was about $30 \%$. The glass cloth maintained its weaving density throughout the preparation of the composite plate. Two types of specimens were cut out from the composite plate to make their tensile direction as warp and weft directions. The shape of the specimen is shown in Fig. 2.

\subsection{Measurment}

Specimens were subjected to the tensile test at a tensile speed of $1 \mathrm{~mm} / \mathrm{min}$ using an Instron universal testing machine (model 4206). During the tensile test, specimens were video-recorded to monitor the appearance of transverse microfracture. Tensile measurements for each silane concentration were carried out for more than five specimens.

\subsection{Determination of Microfracture}

The transverse microfracture was determined by an image analyzer(PIAS LA-500) combined with a micro. computer according to the procedure described in the previous paper [23], observing a scattering of light from the cracking part of the specimen. To determine its appearance, the image processing was carried out as follows. The picture of the specimen recorded on a video 

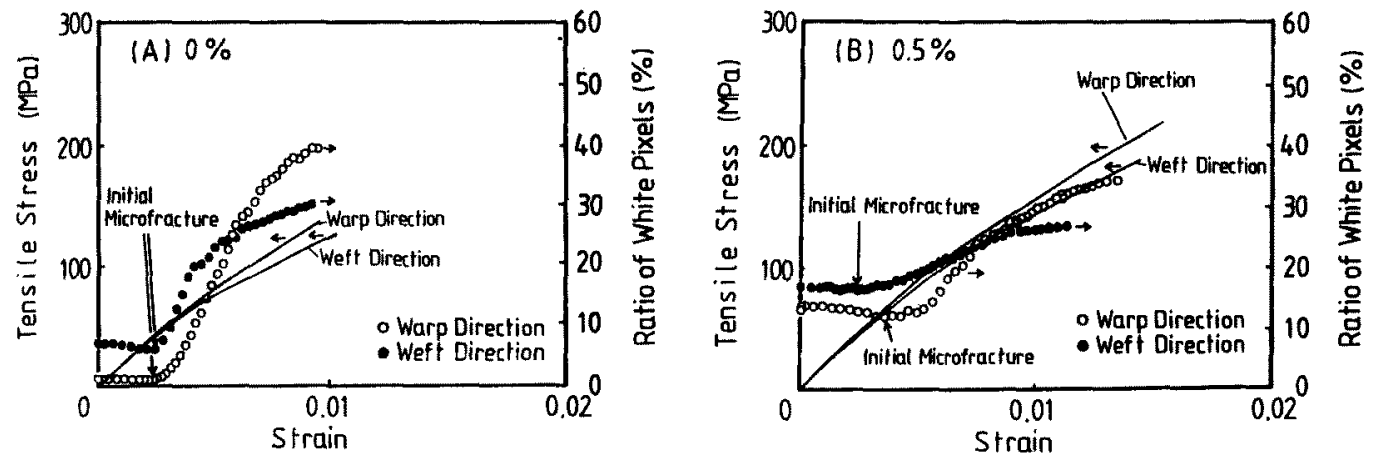

Fig. 3 Stress-strain curve and ratio of white pixels: (A), without AnPS-treatment; (B), treated with $0.5 \%$ AnPs.

tape was taken into the image analyzer. In order to detect the microfracture clearly, an edge detection was at first carried out along to the tensile direction to detect bright lines running to the transverse direction. Secondly, the brightness of the picture was transformed to the binary brightness. Finally, the number of white pixels were counted. A series of image analysis was carried out for the picture at every 2 seconds of the tensile test. The point of initial microfracture was decided as the begin. ning of the increase in point of the number of white pixels. The stress and strain in the specimen were measured when the initial microfracture occurred.

\section{Results}

\subsection{Stress-Strain Properties}

Typical stress-strain curves in tensile tests for treated and nontreated samples are shown in Fig. 3 . The glass cloth in specimens was treated with silane at $0.5 \%$. The ratio of white pixels which relates to the number of transverse microfracture was also plotted in the figure. The silane coupling treatment changed some kinds of mechanical properties; tensile modulus, tensile strength, knee point and initial microfracture stress or strain.

The tensile modulus changed with silane concentration as shown in Fig.4. It varied with the concentration in both tensile directions. The silance treatment at low concentrations was ineffective on the tensile modulus. The tensile modulus increased at concentrations higher than $0.2 \%$. The concentrations higher than $0.5 \%$ gave no additional effect on the tensile modulus. The tensile modulus along warp direction was higher than that along weft direction for most silane concentations.

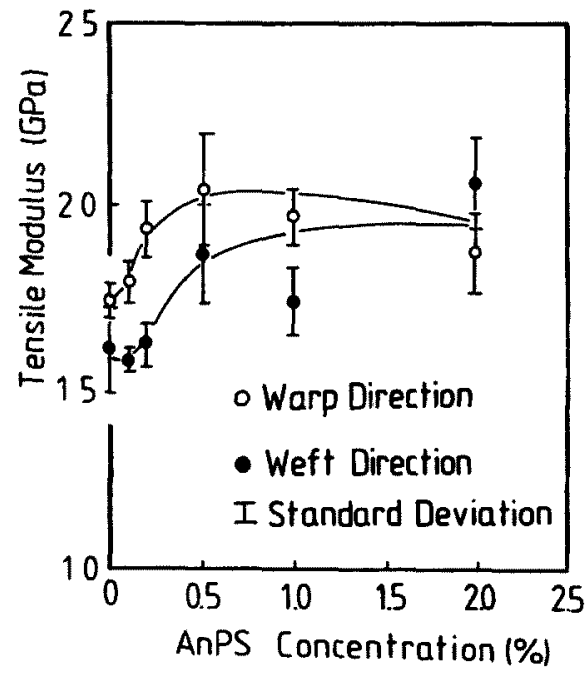

Fig. 4 Effect of AnPS concentration on tensile modulus.

\subsection{Initial Microfracture}

Fig. 5 shows the changes in initial microfracture stress with silane concentration. Regardless of the tensile direction, the initial microfracture strss increased with silane treatment at concentrations above $0.2 \%$ while the silane treatment was ineffective on the initial microfracture stress at concentrations below $0.2 \%$. There was no additional effect of concentration on the initial microfrac ture stress at concentrations above $1 \%$. The total im provement of the initial microfracture stress of warp direction was higher than that of weft direction. The ini. tial microfracture stress of warp direction was smaller than that of weft direction at concentrations below $0.2 \%$, whereas the former became larger than the latter at high. er concentrations 


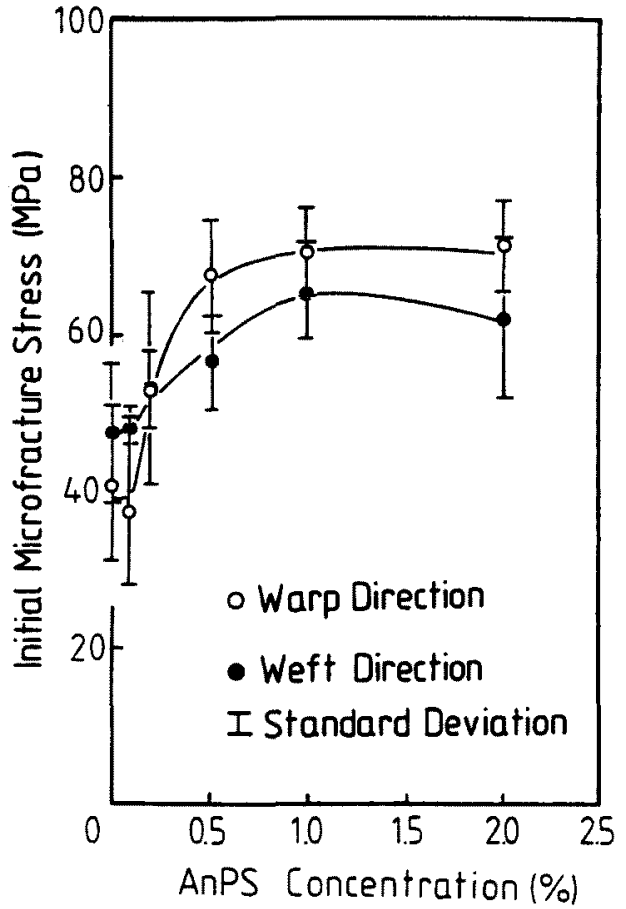

Fig. 5 Effect of AnPS concentration on initial micro. fracture stress.

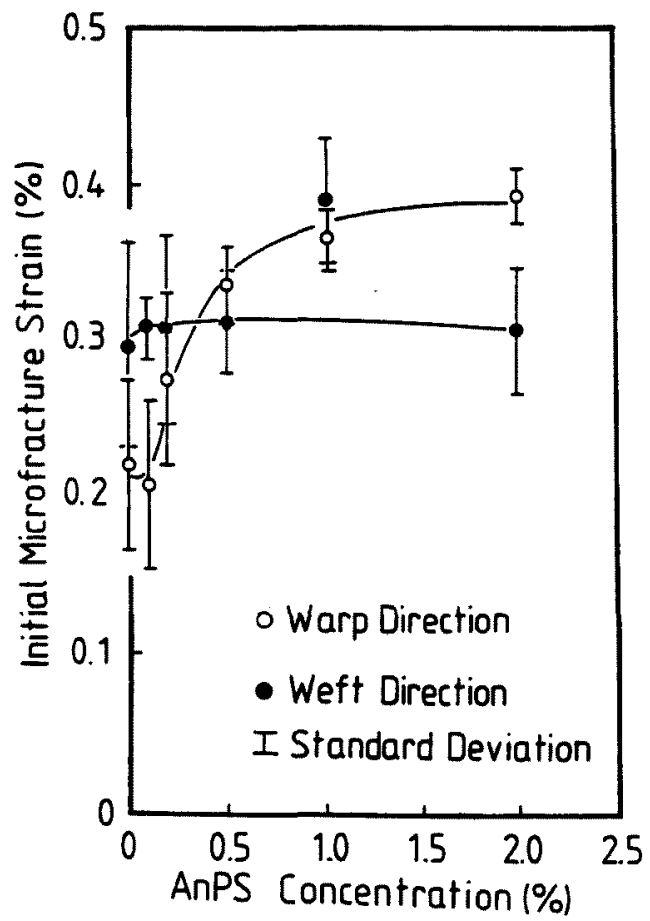

Fig. 6 Effect of AnPS concentration on initial microfracture strain.
Fig. 6 Shows the effect of silane concentration on the initial microfracture strain. In the case of warp direction, the initial microfracture strain increased with silane concentration above $0.2 \%$ while the silane treatment was ineffective at concentrations below $0.2 \%$. The effect of concentration on the improvement of initial microfracture strain became smaller as the concentration became high. er. The total improvement of initial microfracture strain of weft direction was much smaller than that of warp direction. It was almost constant regardless of the silane concentration, and was higher than that of warp direc. tion at concentrations below $0.5 \%$. With the treatment at high silane concentrations the microfracture strain of warp direction became higher than that of weft direction.

\section{Discussion}

Two important results were obtained in this study. One was that the mechanical properties at the initial microfracture were improved with the silane treatment. The other was that the improvement was different between tensile directions due to the fabric structre.

The former reflected the improvement of interfacial strength by silane treatment. As shown in Figs. 5 and 6 . the increases in initial microfracture stress and strain are virtually ascribed to the mechanical improvement of interface by the silane treatment at concentrations above $0.2 \%$. The interfacial reinforcement with silane was ineffective at concentrations below $0.2 \%$. The concentrations above $1 \%$ seem to affect little for the additional interfacial reinforcement. This tendency is similar to the change in interfacial transmissibility with silane concen. tration at the interface between glass fibers and epoxy resin using a modified single filament method, as described in the previous papers $[16,17)$.

The interfacial treansmissibility indicates the extent of shear stress transfer from matrix to glass fiber through the interface. Such a similarity found in both tests sug. gests that the same reinforcement mechanism occurs even in the transverse microfracture targeted in this report. The change in interfacial transmissibility with silane concentration exhibits the presence of different reinforcement mechanisms with respect to the interfacial structure of silane condensates on the glass fibers. If the situation is the same for the plain-woven glass cloth composite, surface wettability theory $(<0.2 \%)$, chemical bonding theory $(>0.2 \%,<1 \%)$, and deformable layer theory 


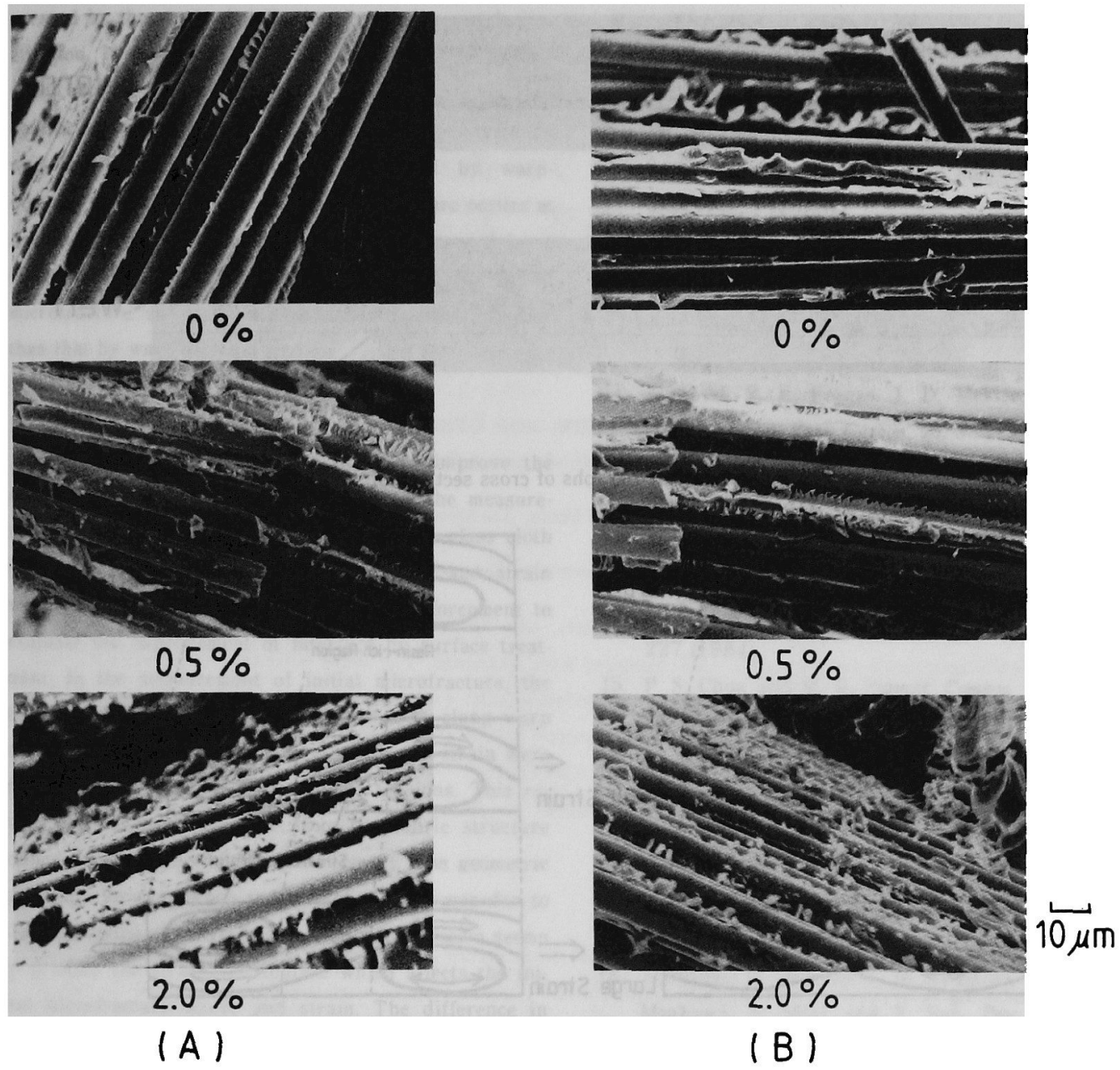

Fig. 7 SEM micrograph of fracture surface: Tensile test along (A), warp direction; (B), weft direction.

$(>1 \%)$ become applicable at the characteristic silane concentration.

The drawing direction in tensile test, however, made the initial microfracture stress and strain altered even at the same silane concentration. The total changes in initial microfracture stress and strain with silane concentration were smaller in weft direction than that in warp direction.

After the tensile test, the fracture surfaces of specimens were observed with SEM to confirm the adhesion between glass fibers and epoxy resin for warp and weft fibers. Fig. 7 shows that the cohesive fracture at resin was mainly observed on both fibers with silane treatment at higher concentrations. This means that the adhesion by silane is effective on reinforcement irrespective of warp and weft. Moreover, there were no differences between warp and weft for weaving density, number of fila ments of a yarn and diameter of filament. The difference in initial microfracture between tensile directions was eventually caused by the different fabric structures.

Fig. 8 shows optical micrographs of cross sections along the warp and weft directions. No difference be tween warp and weft was observed in dispersion of filaments in a yarn, and only a geometrical difference was found between warp and weft yarns. The weft was spread widely and shaped flat, whereas the warp was less spread, and the weft was more bent than the warp. Such a difference in fabric structure arose from the fab- 

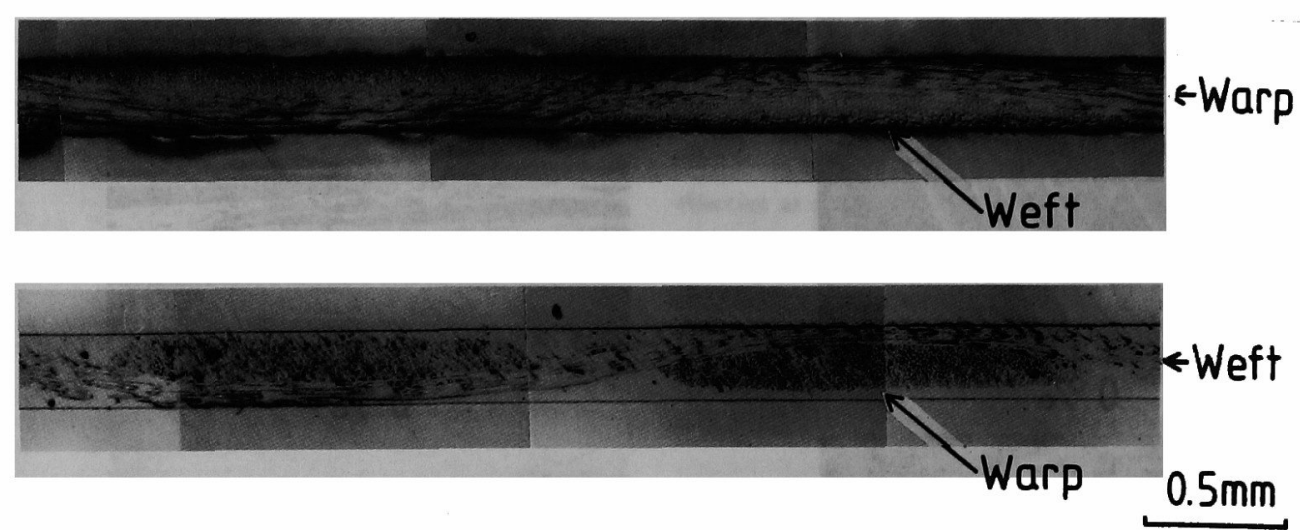

Fig. 8 Optical micrographs of cross sections of specimens.

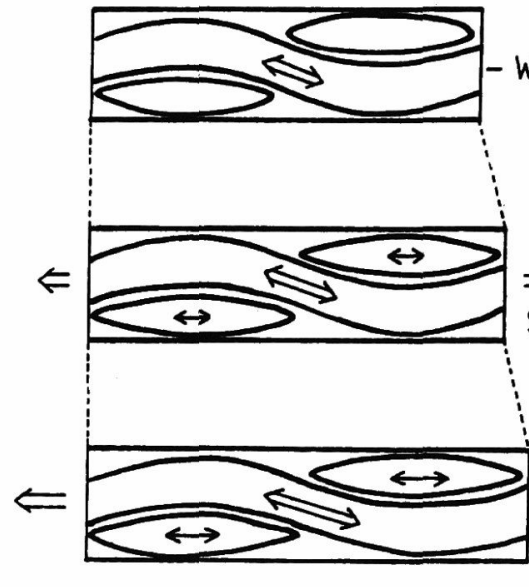

Warp Direction Tensile Test

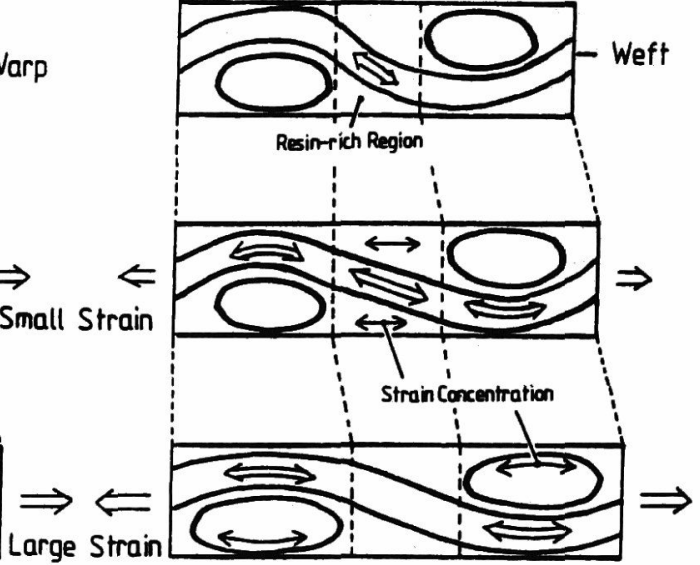

Weft Direction Tensile Test

Fig. 9 Schematic of deformation of specimens.

rication procedure of glass cloth, for example, differences in tension between warp and weft and beating motion. It should be noted that resin-rich region is more located along weft direction than along warp direction. Such a localization of matrix resin varies the local volume fraction of fibers and produces different strain distributions for the two tensile directions.

Fig. 9 shows schematics of the strain distributions along warp and weft directions in tensile test. The resin-rich region where transverse fibers are absent is easily deformable. When a small strain is applied to the specimen, the strain in resin-rich region becomes subsequently lower than that in fiber-rich region. In the case of weft direction, there is a larger resin-rich region than that in the case of warp direction. Therefore, the strain in the transverse fiber region, in the case of weft direction, is smaller than that in the case of warp direction.

A sufficient strain is produced in the resin-rich region before the strain of specimen becomes larger. In weft direction, longitudinal fibers are ready to deform from the bending shape to a straight shape at larger strain of specimen. This is because the degree of bending of longitudinal fibers in the case of weft direction is larger than that in the case of warp direction. Therefore, the strain is easily produced in the transverse fiber region in the case of weft direction.

As a result, the effect of silane treatment on the initial microfracture strain in the case of weft direction is de- 
pressed by the strain distribution due to the matrix localization. If the initial microfracture occurs at a small strain, that is, there is a weak interface due to a low condentration treatment, the initial microfracture strain by weft-directed tension is higher than that by warpdirected tension. When the initial microfracture occurs at a large strain, there is a strong interface caused by a silane treatment at high concentration, and the initial microfracture strain by weft-directed tension is lower than that by warp-directed tension.

\section{Conclusion}

Silane coupling treatment was found to improve the durability to microfracture as reveled by the measurement of initial microfracture of plain-woven glass cloth composite. The initial microfracture stress and strain were useful as an index of interfacial reinforcement to evaluate the improvement of interface by surface treatment. In the measurement of initial microfracture, the tensile direction is important whether it is along warp or weft. The initial microfracture stress and strain were different for warp- and weft.directed tensions. This re'sult was suggested to arise from the fabric structure rather than the interfacial reinforcement. The geometric difference between warp and weft directions was due to the localization of matrix resin. Such a localization seems to produce the strain distribution which affects the initial microfracture stress and strain. The difference in fabric structure between warp and weft directions is important in interpreting the microfracture phenomena of woven fabric composites.

\section{References}

1. E. P. Plueddemann, P. G. Pape, and H. M. Bank, 41st Annu. Conf. SPI, 2-D-1 (1986).

2. E. P. Plueddemann, 25th ANTEC SPI. 13-D-1 (1986).

3. S. R. Culler, H. Ishida, and J. L. Koenig, J. Colloid Interface Sci., 106, 334 (1985)

4. J. Jang. H. Ishida, and E. P. Plueddemann, SAMPE Quartely, 20 [4], 32 (1989).

5. H. Ishida and J. Gorecki, SAMPE Quarterly, 21 [3], $59(1990)$
6. S. Naviroj, S. R. Culler, J. L. Koenig, and H. Ishida, J. Colloid Interface Sci., 97, 308 (1984).

7. H. Ishida and J. L. Koenig, J. Colloid Interface Sci., 64, 565 (1978).

8. D. Santrach, Proc. Annu. Conf. Reinf. Plast. Compos., 40th, 21C-1 (1985)

9. K. P. McAlea and G. J. Besio, Polym. Compos., 9, 285 (1988).

10. K. P. McAlea and G. J. Besio, ANTEC, '87SPI, 1458 (1987).

11. K. Wolf, R. E. Fornes, J. D. Memory, and R. D. Giebert, Chem. Phys. Carbon, 18, 93 (1982).

12. L. T. Drzal, M. J. Rich, M. F. Koenig, and P. F. Froyd, J. Adhesion, 16, 133 (1983).

13. L. T. Drzal, M. J. Rich, and M. F. Koenig. J. Adhesion, 18, 49 (1985).

14. L. T. Drzal, NASA Conf. Publ. NO. NASA-CP-2334, 227 (1984).

15. P. S. Chua and M. R. Piggott, Compos. Sci. Technol.. 22, 33 (1985).

16. N. Ikuta, Z. Maekawa, H.Hamada, H. Ichihashi, E. Nishio, and I. Abe, "Controlled Interphases in Composite Materials" (H. Ishida. Ed.), p. 757 (1990).

17. H. Hamada, Z. Maekawa, N. Ikuta, H. Ichihashi, and E. Nishio, Proc. Japan-U. S. Conf. Compos. Mater., 535 (1990).

18. M.Suzuki, H. Hakanishi, M. Iwamoto, E. Jinen, $Z$. Maekawa, A. Mori, and F. Sun, Proc. ICCM $6 \&$ ECCM 2, London, Vol. 4-32-C (1987).

19. F. Sun, M. Suzuki, H. Nakanishi, M. Iwamoto, and E. Jinen, Prog. Acous. Emission, 4, 795 (1988).

20. T. Ishikawa and T. -W. Chou, J. Mater. Sci., 17, 3211 (1982)

21. T. Ishikawa and T. W. Chou, J. Compos. Mater., 17,399 (1983).

22. T. Ishikawa and T. -W. Chou, "Progress in Science and Engineering of Composites", (T. Hayashi, K. Kawata, and S. Umekawa, Eds.), ICCM.IV, Tokyo, 489 (1982)

23. T. Morii, T. Tanimoto, Z. Maekawa, H. Hamada, K, Kiyosumi, and H.Ichihashi, Polym. and Polym. Com. pos., in press. 